\title{
Improving the Reconfiguration of Hybrid Power Networks by Combining Genetic Algorithm (GA) with Particle Swarm Optimization (PSO)
}

\author{
Ahmed Alshahir*, Richard Molyet \\ Electrical Engineering and Computer Science Department, University of Toledo, Ohio, USA \\ Email address: \\ ahmed.alshahir@utoledo.edu (A. Alshahir),richard.molyet@utoledo.edu (R. Molyet) \\ ${ }^{*}$ Corresponding author
}

To cite this article:

Ahmed Alshahir, Richard Molyet. Improving the Reconfiguration of Hybrid Power Networks by Combining Genetic Algorithm (GA) with Particle Swarm Optimization (PSO). American Journal of Electrical Power and Energy Systems. Vol. 10, No. 1, 2021, pp. 6-14. doi: $10.11648 /$ j.epes.20211001.12

Received: January 25, 2021; Accepted: February 2, 2021; Published: February 10, 2021

\begin{abstract}
Renewable Energy Sources (RESs) have been growing continuously until they become the second source of electricity after coal. However, most of RESs have intermittent nature of electricity production due to the high dependency on some external conditions like weather which changes seasonally. This intermittent nature has a negative impact on security and stability, voltage profile, and increasing the power losses in radial distribution power networks which contain uncertain power sources. Therefore, this paper presents a novel technique based on Genetic Algorithm (GA) combined with Particle Swarm Optimization (PSO). The goal of utilizing the GA is to track the maximum power point of uncertain power sources such as Solar/Photovoltaic (PV) and Wind Turbine (WT). Then, PSO starts its execution to determine the optimum configuration of power networks in order to minimize the power losses, maintain voltage profile, and increase the overall system stability and security. Different test cases are considered for testing different operation conditions. The simulation work has implemented by using MATLAB 2016b software. The results are tested on standard IEEE 33 bus systems and validated with other conventional method to verify the correctness of the proposed technique. Results show a significant improvement in voltage profile, reduction in the power losses, and hence increment in the overall system stability and security.
\end{abstract}

Keywords: Conventional Energy Sources (CESs), Genetic Algorithm (GA), Particle Swarm Optimization (PSO), Radial Distribution Systems (RDSs), Network Reconfiguration

\section{Introduction}

Nowadays, there are so many issues in the power system networks such as increasing the electricity cost, limiting of Conventional Energy Sources (CESs) for generating electricity, etc. However, using CESs do not always lead to an optimum solution in the Radial Distribution Systems (RDSs) due to the limiting quantity, increasing the fuel cost, harming emissions of burning the fossil fuels which made to the power generation unviable and unsustainable. However, with concerns about the environmental problems and progress, Non-Conventional Energy Sources (N-CESs) such as RESs tend to be one of the optimum solutions. They help the world meet sustainable targets though precaution to access to safe energy, clean, affordable as well as prevent the atmospheric pollution by depleting the fossil fuel [1-3].

Solar/Photovoltaic (PV) and Wind Turbine (WT) are very most promising to supply the load; however, they have intermittent nature of electricity production due to the dependency on weather changes [4,5]. As knowing, WT depends on the wind speed which changes seasonally. Similarly, PV relies on the sun irradiance and the temperature which are changed based on the weather conditions. Installation these generators to the network can affect the power flow distribution in the smart grid. So, power losses and voltage profile of distributed power networks are very critical and can affect the whole power system network. Therefore, network reconfiguration has been proposed in literature to reduce the power losses and enhance voltage profile by applying Artificial Intelligence techniques as well as using 
sectionalizing switch (normally closed) or tie switch (normally opened) [6, 7]. So, penetrating RESs in power networks should consider the issue of the uncertainty of production of RESs due to depending on external conditions.

There are many research contributions for optimizing the configuration of the radial power networks to reduce the power losses and determining the optimum placement of the compensator capacitors for the same purpose. For example, feeder reconfiguration is presented in order to minimize the power losses [8]. In addition, Romero et al. have mentioned a new technique for optimizing the power network reconfiguration in order to reduce the active power losses without performing load flow processing [9]. Moreover, Billinton and Jonnavithula have proposed new formulation for calculating the optimum number of sectionalized switches and the optimum place in network feeders for minimizing the power losses [10].

Moreover, a proposed efficient solution has utilized which focused on the problems that prevent evolutionary algorithms from fulfilling all the objective [11]. The authors presented a new codification algorithm which proved better results in terms of optimization the topology of the radial distribution systems to minimize losses and improve the voltage profile. Furthermore, a new algorithm has been presented for optimizing the reconfiguration of radial distribution systems based on integer coded of Particle Swarm Optimization (PSO) [12]. It considered the historical local optimum configurations for generating new particles. It showed an improvement over the traditional PSO method. It also tested the proposed algorithm on three different distribution systems to validate and verify the work.

In addition, the power flow analysis has been utilized iteratively by testing all switches one by one using a new heuristic model to determine the optimum configuration for reducing the power losses [13]. The technique works by considering all branches initially closed and finding the next loop to be opened by one switch. Then, repeating that with updating the opened switch of each iteration until all loops will be opened. Moreover, Montoya and Ramirez have developed a novel algorithm based on Genetic Algorithm (GA) combined with Minimum Spanning Tree (MST) algorithm. MST utilized for determining the configuration of radial power network to minimize the power losses. Then, GA implemented for determining the optimum position and values of the capacitors to improve the power profile and reduce the power losses [14].

Also, a new method has been proposed for reconfiguring the radial power networks and optimizing the capacitor insertion to maintain the voltage profile within acceptable ranges and to reduce the power losses [15]. The method was based on a simple branch exchange technique. Authors utilized a joint optimization algorithm and used the GA for optimizing the location and size of the capacitors and the sequence of the loop selection process. The authors also applied the simulated annealing algorithm to compare the results as regard to the convergence speed. They tested their proposed technique on 77 bus distribution system and run many tests for different load patterns.

Furthermore, a new approach by using GA has been utilized to solve the placement problem and network reconfiguration problem simultaneously in order to reduce power losses and enhance the voltage profile [16]. In addition, a new technique is proposed based on ant colony algorithm and capacitor placement problem [17]. Ant colony is used for solving the optimal reconfiguration of the network. Capacitor placement problem is also used for reducing the power losses and enhancing the voltage profile of radial power network systems. The authors combined the two means for reducing power losses which are using compensator capacitors and network reconfiguration. Their results proved that using these two means together give better results than using them separately.

On the other hand, Artificial Intelligence and heuristic search techniques have been utilized for improving the optimization techniques in the most research papers which conducted in the last few years. For example, a comparative study has been addressed and compared three novel PSO based techniques for optimizing the steady state performance of power system [18]. It showed that the proposed PSO based techniques are more efficient than the conventional PSO and Evolutionary Algorithms-based techniques in terms of the convergence time and accuracy. Furthermore, a new technique for determining the optimum number and position of switches in radial distribution networks has been developed and presented to reduce the total cost [19]. The proposed method includes both type of switches which are the sectionalizing and breaker switches.

In addition, Moradi et al. have developed methods for optimizing the placement of switches in distribution networks based on economical and reliability calculations for minimizing the total cost and maximizing the reliability of the system [20]. Furthermore, an optimum relocation technique of the sectionalized switches has presented for reducing the interruption cost based on traditional method of solving optimum power flow method [21]. However, Teng and Liu solved the problem based on Ant Colony System (ACS) technique and compared their results with the Genetic Algorithm (GA)-based technique [22]. The authors have proved a significant improvement. Moreover, a new method is proposed for allocating number of switches and locations remotely based on decomposition technique [23]. It demonstrated significant effect to enhance the fault isolation and reconfiguration of the system. Also, a hybrid technique composed of PSO integrated with tangent vector technique is presented for reducing the power losses by optimally solving the power flow [24]. Moreover, a Binary Particle Swarm Optimization (BPSO) method is used with standard IEEE 33 in order to obtain the optimal distribution configuration of the network for minimizing the power losses and voltage profile [25].

The above survey concludes that there are basically two methods for reducing the power losses and maintaining the voltage profile which are using compensator capacitors and reconfiguration of power network sectionalizing switches. It also lists many methods and algorithms for solving the 
optimization problem. Some of them are conventional methods and some are based on Artificial Intelligence and heuristic search techniques. Also, some have worked on the two means of reducing the power losses separately and other methods used a combination of techniques. However, all techniques and algorithms have not considered the uncertainty of some generation sources like RESs. The intermittent nature of such sources causes problem of reliability and may change the results negatively regarding power losses. Therefore, there is still a knowledge gap and immense need for developing new methods that consider penetrating the power networks with sources of uncertainty in power systems.

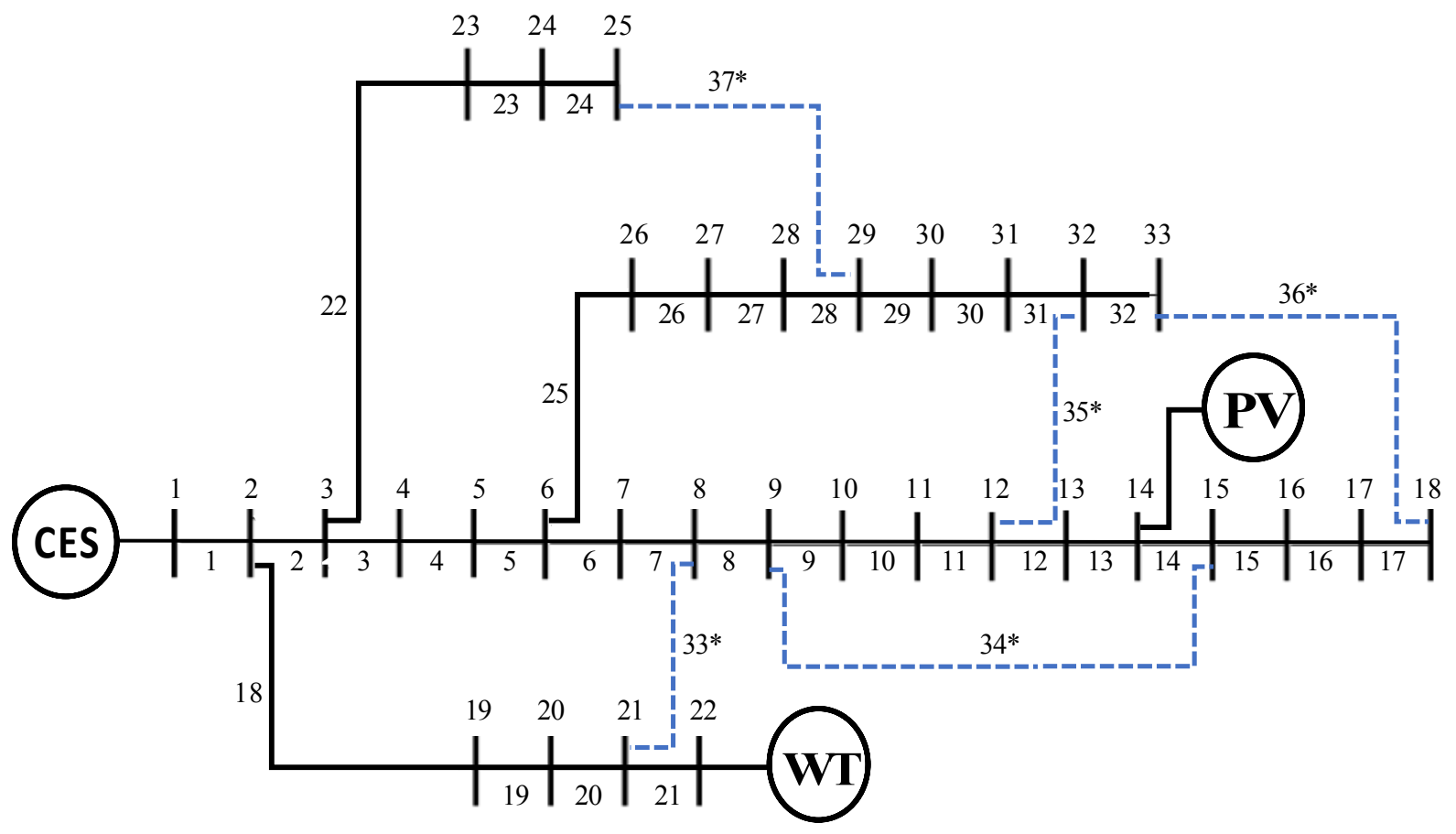

Figure 1. Single line diagram of radial power system with generators and switches.

Table 1. List of used sources.

\begin{tabular}{lll}
\hline Generator Type & Capacity & Location \\
\hline Conventional Energy Source (CES) & $2 \mathrm{MW}$ & Bus 1 \\
Solar/Photovoltaic (PV) & $1 \mathrm{MW}$ & Bus 14 \\
Wind Turbine (WT) & $1 \mathrm{MW}$ & Bus 22 \\
\hline
\end{tabular}

This paper presents a novel method to determine the optimum configuration of the network which has been extended from [25] by considering the inclusion of RESs such as WT and PV power sources of the radial power systems. Also, GA combined with PSO technique are utilized to determine the maximum power point of the RESs and to find the optimum state of sectionalizing switches and tie switches in order to minimize the active power losses and maintain the voltage profile at an acceptable value. This satisfies all system constraints regarding generation and demand for all buses in the network to guarantee the security and reliability of the power network.

The paper is organized as follows: Section 2 presents the methodology of the proposed technique. Section 3 shows and discusses the simulation results. The conclusion of the work will be shown in Section 4 .

\section{Material and Method}

\subsection{Problem Statement}

As it has been introduced above in the introduction, most of the existing solutions of optimizing the power losses by using the reconfiguration in radial power system networks have not considered the case of having uncertain amount of production in generation sources like the case of RESs such as WT and PV generators. So, the problem that is targeted in this research can be defined as optimizing the power losses and maintaining the voltage profile at acceptable ranges in radial power systems which include renewable energy generators.

\subsection{System Description}

The single line diagram which is shown in Figure 1 represents a typical IEEE 33 bus radial power system. Also, it shows the generators and switches which are distributed over the bus system. The solid bold lines represent buses as well as branches which connect buses together in case of connecting switches to be initially closed while the dotted lines show switches to be initially opened. In addition, the network is supplied by the following generators which listed in Table 1.

Also, Table 2 below represents line data, load data as well as the sectionalizing switches and tie switches of the examined 
system. The column Lines in the table represents the number of switches between buses and tie switches of the radial power system. $\mathrm{R}$ is the resistance of the line. $\mathrm{X}$ is the reactance of the line. $\mathrm{Pd}$ is the active demanded power. $\mathrm{Qd}$ is the reactive demanded power. Type represents the bus type which divides into three different numbers such as number 1 is for load bus type, number 2 is for slack or reference bus type (if exist), and number 3 is for generator bus type. Status is the initial status of the 37 switches which categorized as 1 for connected status and 0 for disconnected status. The range of voltages is between 0.9 and $1 \mathrm{pu}$. The base voltage is considered as $12.66 \mathrm{KV}$. This radial power system will be used in testing the proposed technique.

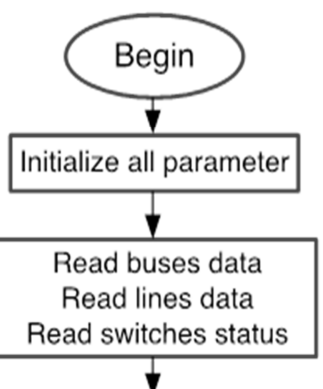

Read irradiance and temperature

Call Genetic algorithm to get the maximum power point

Call Genetic algorithm to get the maximum power point

Update the RES generation based on GA result

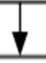

Generate switches configuration

Generate initial swarm

$\nabla$

Calculate fitness of all particles using power flow

Update velocity and position of particles

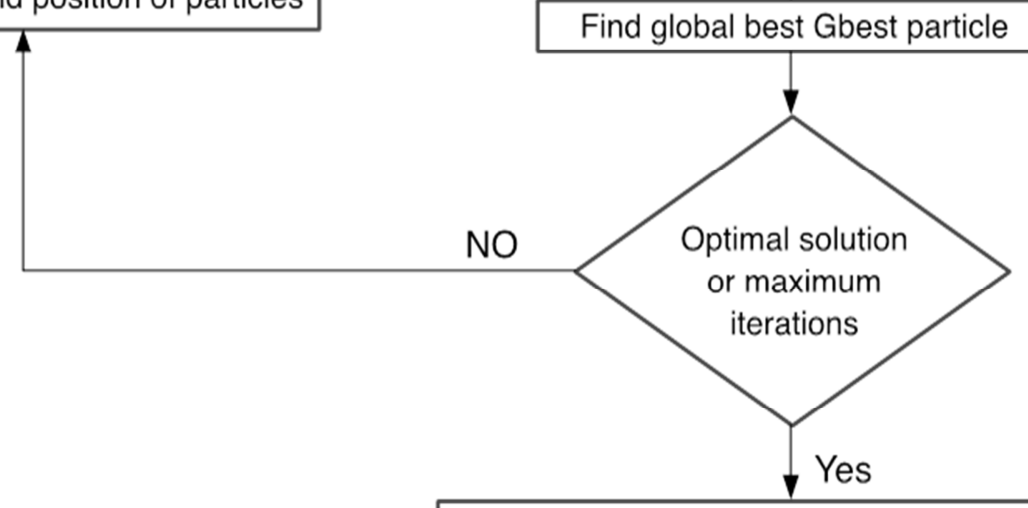

Report active and reactive power and voltages of all buses and final status of all switches

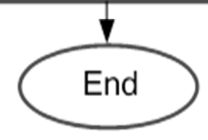

Figure 2. Proposed technique flowchart. 
Table 2. Branches data and sectionalizing switches of system IEEE 33 bus.

\begin{tabular}{|c|c|c|c|c|c|c|c|c|}
\hline Lines & From Bus & To bus & $\mathbf{R}(\Omega)$ & $\mathbf{X}(\Omega)$ & Pd $(k W)$ & Qd $(\mathrm{kW})$ & Type & Status \\
\hline 1 & 1 & 2 & 0.0922 & 0.0477 & 0 & 0 & 3 & 1 \\
\hline 2 & 2 & 3 & 0.4930 & 0.2511 & 100 & 60 & 1 & 1 \\
\hline 3 & 3 & 4 & 0.3660 & 0.1864 & 90 & 40 & 1 & 1 \\
\hline 4 & 4 & 5 & 0.3811 & 0.1941 & 120 & 80 & 1 & 1 \\
\hline 5 & 5 & 6 & 0.8190 & 0.7070 & 60 & 30 & 1 & 1 \\
\hline 6 & 6 & 7 & 0.1872 & 0.6188 & 60 & 20 & 1 & 1 \\
\hline 7 & 7 & 8 & 1.7114 & 1.2351 & 200 & 100 & 1 & 1 \\
\hline 8 & 8 & 9 & 1.0300 & 0.7400 & 200 & 100 & 1 & 1 \\
\hline 9 & 9 & 10 & 1.0400 & 0.7400 & 60 & 20 & 1 & 1 \\
\hline 10 & 10 & 11 & 0.1966 & 0.0650 & 60 & 20 & 1 & 1 \\
\hline 11 & 11 & 12 & 0.3744 & 0.1238 & 45 & 30 & 1 & 1 \\
\hline 12 & 12 & 13 & 1.4680 & 1.1550 & 60 & 35 & 1 & 1 \\
\hline 13 & 13 & 14 & 0.5416 & 0.7129 & 60 & 35 & 1 & 1 \\
\hline 14 & 14 & 15 & 0.5910 & 0.5260 & 120 & 80 & 3 & 1 \\
\hline 15 & 15 & 16 & 0.7463 & 0.5450 & 60 & 10 & 1 & 1 \\
\hline 16 & 16 & 17 & 1.2890 & 1.7210 & 60 & 20 & 1 & 1 \\
\hline 17 & 17 & 18 & 0.7320 & 0.5740 & 60 & 20 & 1 & 1 \\
\hline 18 & 2 & 19 & 0.1640 & 0.1565 & 90 & 40 & 1 & 1 \\
\hline 19 & 19 & 20 & 1.5042 & 1.3554 & 90 & 40 & 1 & 1 \\
\hline 20 & 20 & 21 & 0.4095 & 0.4784 & 90 & 40 & 1 & 1 \\
\hline 21 & 21 & 22 & 0.7089 & 0.9373 & 90 & 40 & 1 & 1 \\
\hline 22 & 3 & 23 & 0.4512 & 0.3083 & 90 & 40 & 3 & 1 \\
\hline 23 & 23 & 24 & 0.8980 & 0.7091 & 90 & 50 & 1 & 1 \\
\hline 24 & 24 & 25 & 0.8960 & 0.7011 & 420 & 200 & 1 & 1 \\
\hline 25 & 6 & 26 & 0.2030 & 0.1034 & 420 & 200 & 1 & 1 \\
\hline 26 & 26 & 27 & 0.2842 & 0.1447 & 60 & 25 & 1 & 1 \\
\hline 27 & 27 & 28 & 1.0590 & 0.9337 & 60 & 25 & 1 & 1 \\
\hline 28 & 28 & 29 & 0.8042 & 0.7006 & 60 & 20 & 1 & 1 \\
\hline 29 & 29 & 30 & 0.5075 & 0.2585 & 120 & 70 & 1 & 1 \\
\hline 30 & 30 & 31 & 0.9744 & 0.9630 & 200 & 600 & 1 & 1 \\
\hline 31 & 31 & 32 & 0.3105 & 0.3619 & 150 & 70 & 1 & 1 \\
\hline 32 & 32 & 33 & 0.3410 & 0.5302 & 210 & 100 & 1 & 1 \\
\hline $33 *$ & 21 & 8 & 2.0000 & 2.0000 & - & - & - & 0 \\
\hline $34 *$ & 9 & 15 & 2.0000 & 2.0000 & - & - & - & 0 \\
\hline $35^{*}$ & 12 & 32 & 2.0000 & 2.0000 & - & - & - & 0 \\
\hline $36^{*}$ & 18 & 33 & 0.5000 & 0.5000 & - & - & - & 0 \\
\hline $37 *$ & 25 & 29 & 0.5000 & 0.5000 & - & - & - & 0 \\
\hline
\end{tabular}

$*$ mark indicates the tie switches, substation voltages $=12.66 \mathrm{KV}$

\subsection{The Proposed Solution}

The proposed solution utilizes GA to determine the maximum power point of the WT and PV generators at the operation conditions. Then, the data of both generators are updated based on the GA results. After GA completes the execution, the PSO starts its execution until reaching to one of the termination conditions which either the optimum solution or the maximum of iterations reaches. Figure 2 charts the logic flow of the proposed solution.

In order to get the optimum power of the system, it is necessary to determine the optimum voltage and optimum current based on the equations (1) and (2).

$$
\begin{gathered}
I_{s c}=I_{s c}^{*}\left(G / G^{*}\right)+\propto_{1}\left(T-T^{*}\right) \\
V_{o c}=V_{o c}^{*}+\propto_{2}\left(T-T^{*}\right)-\left(I_{s c}-I_{s c}^{*}\right)
\end{gathered}
$$

where $I_{s c}$ is short-circuit current, $V_{o c}$ is open-circuit voltage at the intensity $G$ and cell temperature $T$ of the PV and WT, $\propto_{1}$ is the temperature coefficient of current. Also, $\propto_{2}$ is the temperature coefficient of voltage, $I_{s c}^{*}$ and $V_{o c}^{*}$ are the array short circuit current and open-circuit voltage at the reference intensity $G^{*}$ and cell temperature $T^{*}$ of the PV and WT. Therefore, linear dependency equation between optimal operation current and short circuit current is given in (3). Also, the optimal operation voltage relative to the open circuit voltage is expressed in (4). The maximum power point equation is also expressed in (5).

$$
\begin{gathered}
I_{o p}=K_{i} * I_{s c} \\
V_{o p}=K_{v} * V_{o c} \\
M a x P_{o p}=I_{o p} * V_{o p}
\end{gathered}
$$

where $K_{i}$ and $K_{v}$ are proportional factors of the current and voltage respectively [26].

After determining the optimum power at specific temperature and irradiance, the generation of $\mathrm{PV}$ is updated in the bus data and the same for WT generator as regard to the optimum wind speed. Then, the PSO is started to look for the global best values of switch configuration based on the fitness value which represent the minimum power losses. 


\section{Simulation Results}

The proposed technique utilizes GA combined with PSO to achieve the reconfiguration of the network to reduce the power losses. The objective of GA is to determine the optimum maximum power of the PV and WT at given operating conditions. In these results, four test cases have been considered and validated. In addition, power losses and minimizing the voltage are compared among all the cases. Make sure that all cases are based on Figure 1 and default switches' statuses listed on Table 2. These four cases are listed as follows: the CES, PV and WT generators are taken into consideration in case 1 . In case 2 , the WT is neglected. Also, the PV is not considered in case 3. Finally, only the CES has been considered in case 4 .

\subsection{Test Case 1}

Based on Figure 1, in this test case, the CES is connected at bus $1, \mathrm{PV}$ at bus 14 and WT at bus 22. Table 3 shows the status of switches before and after the reconfiguration along with noting that the switches before the reconfiguration are connected as shown in Table 2. Also, Figure 3 are demonstrated the voltage profile chart. All the switches are connected (initially closed) except switches (tie switches) 33-37 are disconnected (initially opened). After the reconfiguration, it is seen that the set switches (tie switches) $9,13,18,30$, and 37 are considered to be off or disconnected and all other switches set to be on or connected. In addition, it is shown the decrease in power losses reduction to be $15.378 \%$ since it is decreased from $214.43 \mathrm{~kW}$ to be 181.455 $\mathrm{kW}$. The increase in the voltage profile from $0.94612 \mathrm{pu}$, in its earlier configuration, to $0.97157 \mathrm{pu}$ (out of 1) after reconfiguration.

\subsection{Test Case 2}

In this test case, the CES is connected at bus 1 and PV at bus 14 without considering WT. As it is shown in Table 4 and Figure 4, before the reconfiguration, switches are connected as the default switches, which already indicated in Table 2. After reconfiguration, switch $8,20,28,30$, and 34 are considered to be disconnected and all other switches are connected. Based on that, it shows decrease in power losses to be $11.1473 \%$ and increase in the voltage profile as well which reaches 0.96205 pu.

Table 3. Simulation results of 33 bus Distribution network the results for test case 1 .

\begin{tabular}{lll}
\hline Case 1: (CES, PV, WT) & Before Reconfiguration & After Reconfiguration \\
\hline Tie Switches & $\mathrm{S} 33, \mathrm{~S} 34, \mathrm{~S} 35, \mathrm{~S} 36, \mathrm{~S} 37$ & $\mathrm{~S} 9, \mathrm{~S} 13, \mathrm{~S} 18, \mathrm{~S} 30, \mathrm{~S} 37$ \\
Power loss & $214.43 \mathrm{~kW}$ & $181.455 \mathrm{~kW}$ \\
Loss Reduction & - & $15.378 \%$ \\
Minimum Voltage & $0.94612 \mathrm{pu}$ & $0.97157 \mathrm{pu}$ \\
\hline
\end{tabular}

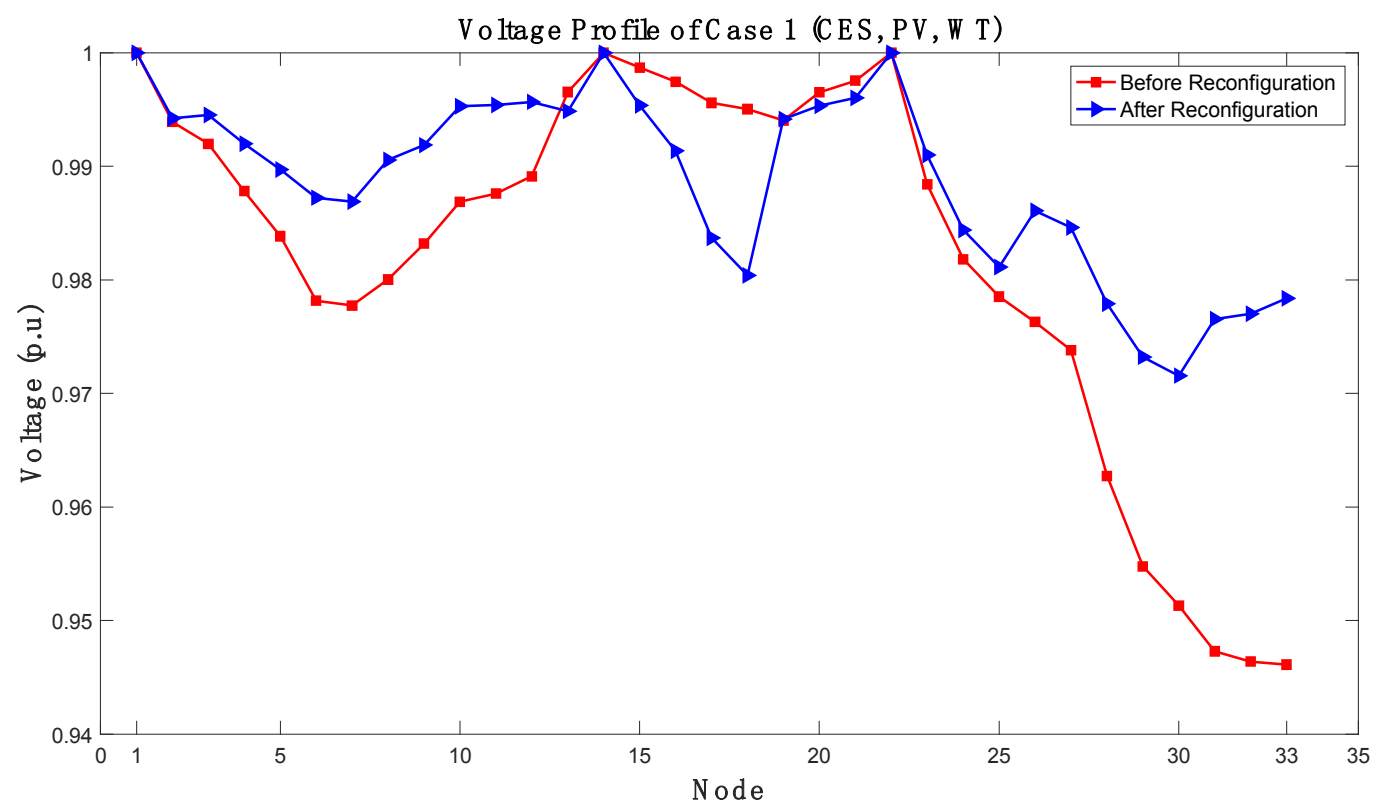

Figure 3. Voltage profile of case 1 before and after reconfiguration.

Table 4. Simulation results of 33 bus Distribution network the results for test case 2.

\begin{tabular}{lll}
\hline Case 2: (CES, PV) & Before Reconfiguration & After Reconfiguration \\
\hline Tie Switches & $\mathrm{S} 33, \mathrm{~S} 34, \mathrm{~S} 35, \mathrm{~S} 36, \mathrm{~S} 37$ & $\mathrm{~S} 8, \mathrm{~S} 20, \mathrm{~S} 28, \mathrm{~S} 30, \mathrm{~S} 34$ \\
Power loss & $220.7825 \mathrm{~kW}$ & $196.1711 \mathrm{~kW}$ \\
Loss Reduction & - & $11.1473 \%$ \\
Minimum Voltage & $0.94583 \mathrm{pu}$ & $0.96205 \mathrm{pu}$ \\
\hline
\end{tabular}




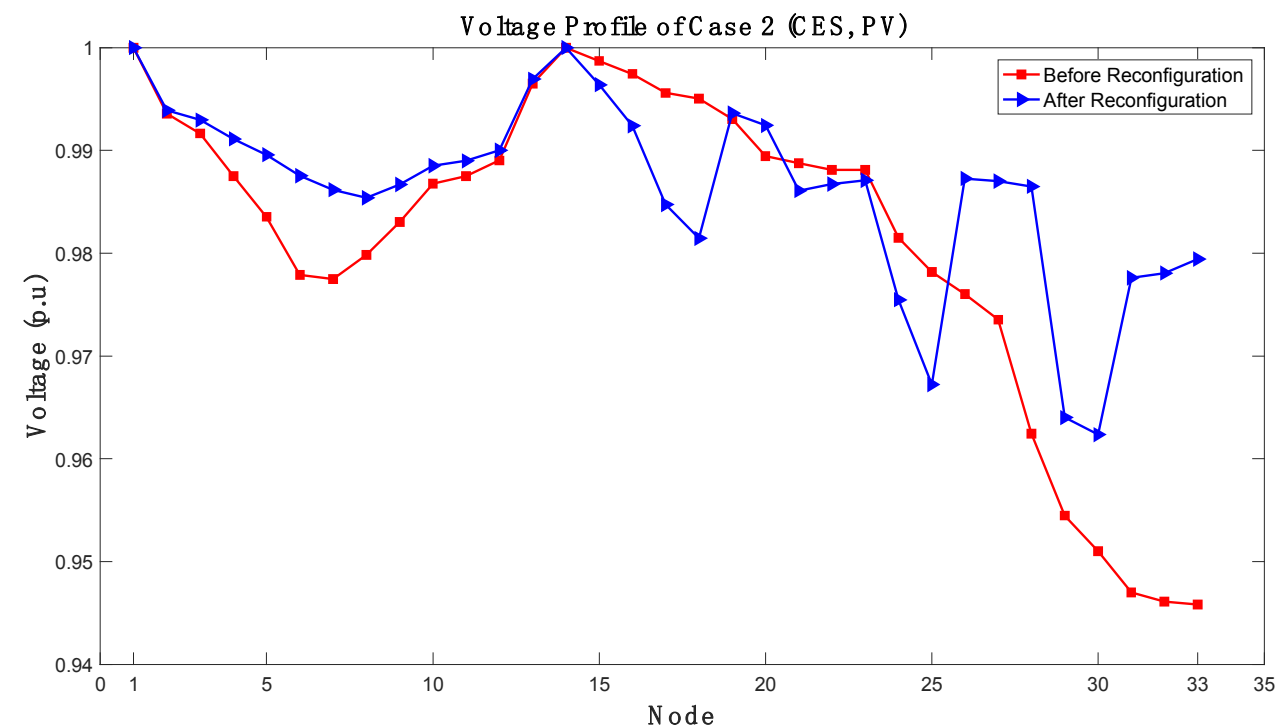

Figure 4. Voltage profile of case 2 before and after reconfiguration.

\subsection{Test Case 3}

The CES and WT are connected at bus 1 and bus 22 respectively while the $\mathrm{PV}$ is not considered in this test case. In Table 5 and Figure 5, the reconfiguration of switches before and after are shown. After the reconfiguration, switch 8, 14, 18,
31 , and 37 are considered to be disconnected and all others are connected. They are suggested to improve the power losses and the voltage profile as well. The power losses decreased by $30.0509 \%$ and the voltage profile increased to $0.95147 \mathrm{pu}$ as well.

Table 5. Simulation results of 33 bus Distribution network the results for test case 3.

\begin{tabular}{lll}
\hline Case 3: (CES, WT) & Before Reconfiguration & After Reconfiguration \\
\hline Tie Switches & $\mathrm{S} 33, \mathrm{~S} 34, \mathrm{~S} 35, \mathrm{~S} 36, \mathrm{~S} 37$ & $\mathrm{~S} 8, \mathrm{~S} 14, \mathrm{~S} 18, \mathrm{~S} 31, \mathrm{~S} 37$ \\
Power loss & $298.9289 \mathrm{~kW}$ & $209.0981 \mathrm{~kW}$ \\
Loss Reduction & - & $30.0509 \%$ \\
Minimum Voltage & $0.92057 \mathrm{pu}$ & $0.95147 \mathrm{pu}$ \\
\hline
\end{tabular}

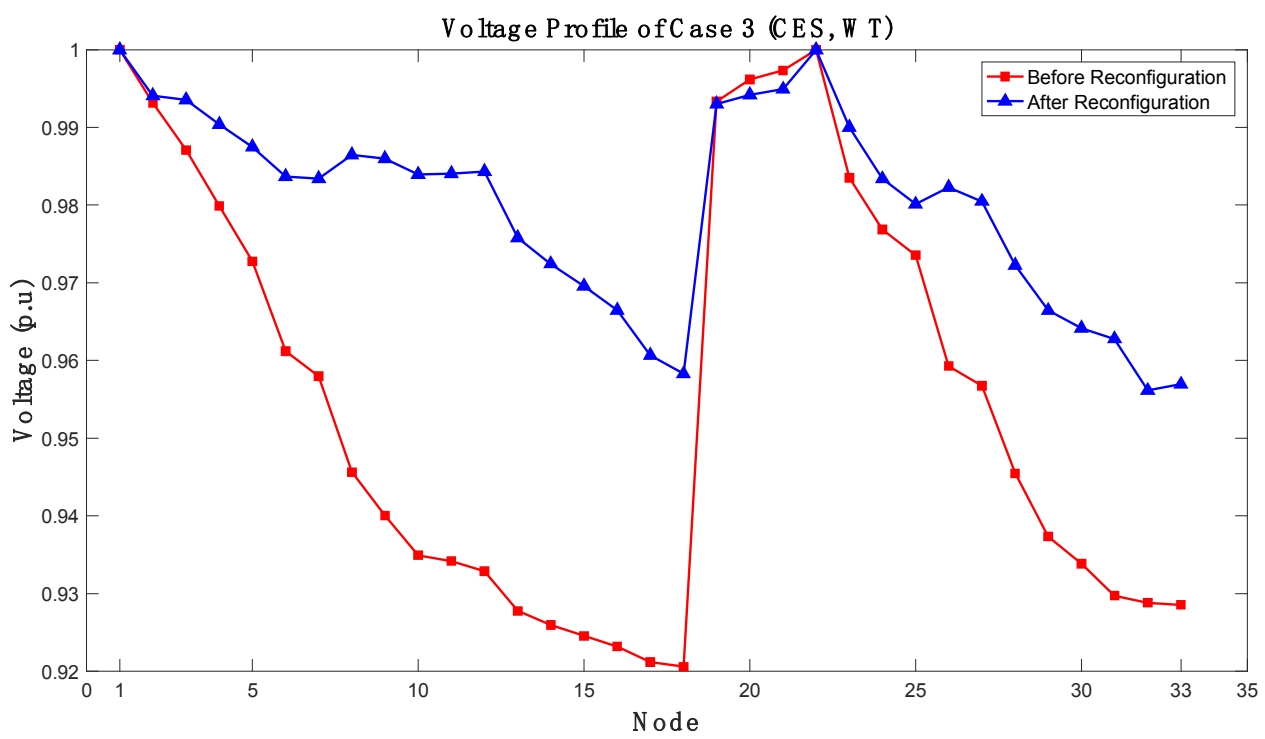

Figure 5. Voltage profile of case 3 before and after reconfiguration.

Table 6. Simulation results of 33 bus Distribution network the results for test case 4.

\begin{tabular}{lll}
\hline Case 4: (CES only) & Before Reconfiguration & After Reconfiguration \\
\hline Tie Switches & $\mathrm{S} 33, \mathrm{~S} 34, \mathrm{~S} 35, \mathrm{~S} 36, \mathrm{~S} 37$ & $\mathrm{~S} 7, \mathrm{~S} 9, \mathrm{~S} 14, \mathrm{~S} 32, \mathrm{~S} 37$ \\
Power loss & $306.1629 \mathrm{~kW}$ & $259.5106 \mathrm{~kW}$ \\
Loss Reduction & - & $15.2377 \%$ \\
Minimum Voltage & $0.92017 \mathrm{pu}$ & $0.94418 \mathrm{pu}$ \\
\hline
\end{tabular}




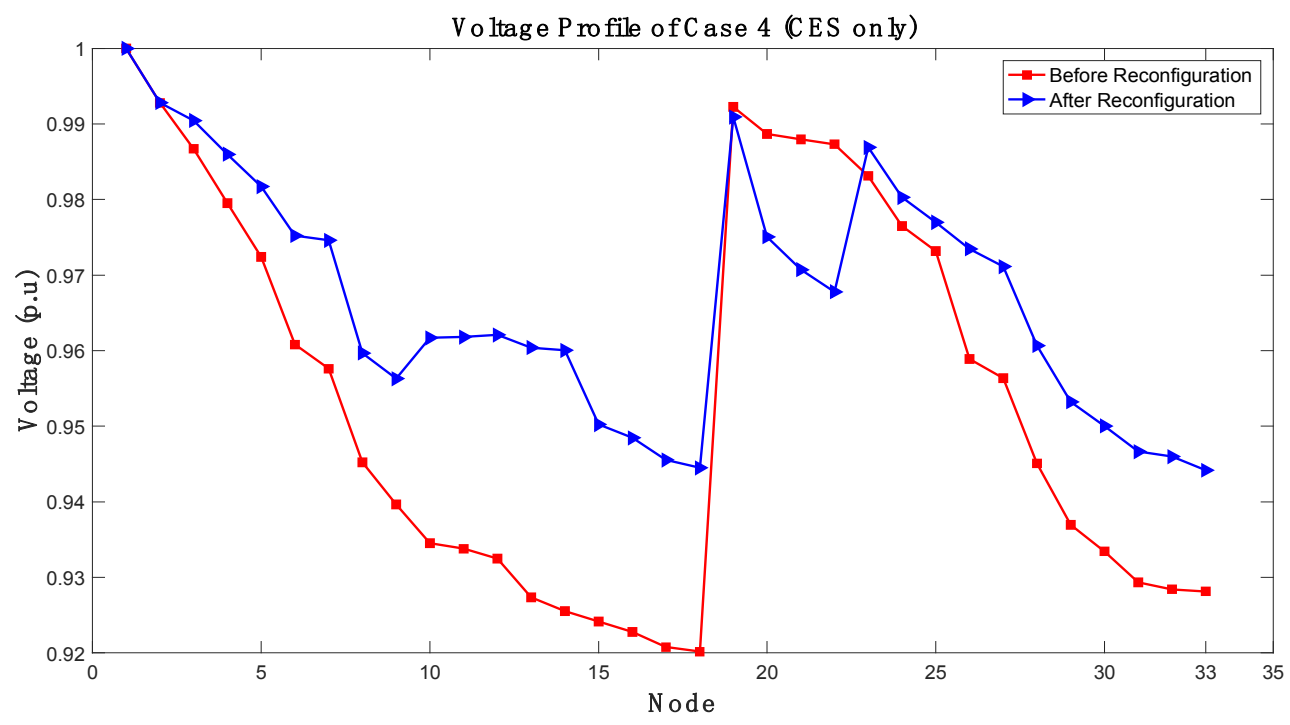

Figure 6. Voltage profile of case 4 before and after configuration.

Table 7. Comparison of simulation results for IEEE 33 bus system

\begin{tabular}{|c|c|c|c|c|c|}
\hline \multicolumn{2}{|c|}{ Cases \& Methods } & $\begin{array}{l}\text { Tie Switches Before } \\
\text { Reconfiguration }\end{array}$ & $\begin{array}{l}\text { Tie Switches After } \\
\text { Reconfiguration }\end{array}$ & $\begin{array}{l}\text { Voltage Profile Before } \\
\text { Reconfiguration (pu) }\end{array}$ & $\begin{array}{l}\text { Voltage Profile After } \\
\text { Reconfiguration (pu) }\end{array}$ \\
\hline $\begin{array}{l}\text { Case } 1 \\
\text { Method }\end{array}$ & $\begin{array}{l}\text { CES, PV, WT } \\
\text { GA-PSO }\end{array}$ & S33, S34, S35, S36, S37 & S9, S13, S18, S30, S37 & 0.94612 & 0.97157 \\
\hline $\begin{array}{l}\text { Case } 2 \\
\text { Method }\end{array}$ & $\begin{array}{l}\text { CES, PV } \\
\text { GA-PSO }\end{array}$ & $\mathrm{S} 33, \mathrm{~S} 34, \mathrm{~S} 35, \mathrm{~S} 36, \mathrm{~S} 37$ & $\mathrm{~S} 8, \mathrm{~S} 20, \mathrm{~S} 28, \mathrm{~S} 30, \mathrm{~S} 34$ & 0.94583 & 0.96205 \\
\hline $\begin{array}{l}\text { Case } 3 \\
\text { Method }\end{array}$ & $\begin{array}{l}\text { CES, WT } \\
\text { GA-PSO }\end{array}$ & S33, S34, S35, S36, S37 & S8, S14, S18, S31, S37 & 0.92057 & 0.95147 \\
\hline $\begin{array}{l}\text { Case } 4 \\
\text { Method }\end{array}$ & $\begin{array}{l}\text { CES only } \\
\text { GA-PSO }\end{array}$ & S33, S34, S35, S36, S37 & S7, S9, S14, S32, S37 & 0.92017 & 0.94418 \\
\hline $\begin{array}{l}{[25]} \\
\text { Method }\end{array}$ & $\begin{array}{l}\text { CES only } \\
\text { BPSO }\end{array}$ & S33, S34, S35, S36, S37 & S7, S9, S14, S32, S37 & 0.91075 & 0.94234 \\
\hline
\end{tabular}

\subsection{Test Case 4}

In this case, only the CES is used which is connected at bus 1. After reconfiguration, switch $7,9,14,32$, and 37 are considered in this case. Table 6 and Figure 6 show that the proposed method reduced the power losses by $15.2377 \%$ and improved the voltage profile to be $0.94418 \mathrm{pu}$.

\subsection{Validation}

In order to verify the correctness of the proposed method, the same reconfigurations and parameters have been validated and compared with results of [25] in which the reconfiguration was based on the method of (BPSO) in case using CES. The voltage profile has reached 0.94234 pu after reconfiguration. Table 7 below summarizes and compares the results for all the four cases as well as the results in [25].

\section{Conclusion}

This paper presented a novel method for optimizing the reconfiguration of switches of radial power network in case of inclusion of uncertain power sources. The new method has utilized GA combined with PSO for determining the maximum power point of the WT and PV and finding the optimal configuration. Therefore, the power losses are minimized, and the voltage profile is maintained. MATLAB $2016 \mathrm{~b}$ software is used for modeling and simulating the radial power system of IEEE 33 busses. Different conditions are tested including having CES with hybrid PV and WT, CES with PV, CES with WT and finally CES alone. The results of all test cases have indicated a significant improvement in voltage profile and reduction of power losses.

Moreover, the performance of the proposed system has been compared with other work for validation. The comparison shows that the new method on the proposed system is more effective and able to grant more voltage profile. The maximum voltage profile improvement has happened in case 1 and reached 0.97157 pu which is recommended to be applied in real distribution networks.

\section{References}

[1] M. Amer, A. Namaan, and N. K. M'sirdi, "Optimization of hybrid renewable energy systems (HRES) using PSO for cost reduction," Energy Procedia, vol. 42, pp. 318-327, Jan 2013.

[2] I. B. Hamida, S. B. Salah, F. Msahli, and M. F. Mimouni, "Optimal network reconfiguration and renewable DG integration considering time sequence variation in load and DGs," Renewable energy, vol. 121, pp. 66-80, 2018. 
[3] O. H. Mohammed, Y. Amirat, and M. Benbouzid, "Particle swarm optimization of a hybrid wind/tidal/PV/battery energy system. Application to a remote area in Bretagne France,” Energy Procedia, 162, 87-96, 2019.

[4] M. R. Javadi, K. Mazlumi, and A. Jalilvand, "Application of GA, PSO and ABC in optimal design of a stand-alone hybrid system for north-west of Iran," In2011 7th International Conference on Electrical and Electronics Engineering (ELECO), pp. 203-211, 2011, IEEE.

[5] A. Alshahir, W. Collings, R. Molyet, and R. Khanna, "Transient enhancement of smart grid using SMES controlled by PID and fuzzy logic control," Engineering and Applied Sciences, vol. 5, no. 3, pp. 56-65, 2020.

[6] G. A. Eboda, A. W. Eboda, and S. B. Femi, "Development of a power flow model for optimal location of distributed generators in electrical distribution system," Development, vol 7, no. 9, pp. 11-19, 2017.

[7] H. Hong, Z. Hu, R. Guo, J. Ma, and J. Tian, "Directed graph-based distribution network reconfiguration for operation mode adjustment and service restoration considering distributed generation," Journal of Modern Power Systems and Clean Energy, vol. 5, no. 1, pp. 142-149, 2017.

[8] I. Roytelman, V. Melnik, S. S. H. Lee, and R. G. Lugu, "Multiobjective feeder reconfiguration by distribution management system," IEEE Transactions on Power Systems, vol. 11, no. 2, pp. 661-667, 1996.

[9] E. Romero, J. L. Martinez-Ramos, A. Gdmez, and A. Urbano, "Optimal reconfiguration of distribution networks for power loss reduction," 2001 IEEE Porto Power Tech Proceedings (Cat No. 01EX502), vol. 3. 2001. IEEE.

[10] R. Billinton and S. Jonnavithula, "Optimal switching device dlacement in radial distribution systems," IEEE Transactions on Power Delivery, vol. 11, no. 3: 1646-1651, 1996.

[11] E. M. Carreno, R. Romero, and A. Padilha-Feltrin, "An efficient codification to solve distribution network reconfiguration for loss reduction problem," IEEE Transactions on Power Systems, vol. 23, no. 4, pp. 1542-1551, 2008.

[12] W. C. Wu and M. S. Tsai, "Application of enhanced integer coded particle swarm optimization for distribution system feeder reconfiguration," IEEE Transactions on Power Systems, vol. 26, no. 1, pp. 1-9, 2011.

[13] F. V. Gomes et al., "A new distribution system reconfiguration approach using optimum power flow and sensitivity analysis for loss reduction. IEEE Transactions on Power Systems, vol. 21, no. 4, pp. 1616-1623, 2006.

[14] D. P. Montoya and J. M. Ramirez, "Reconfiguration and optimal capacitor placement for losses reduction," 2012 Sixth IEEE/PES Transmission and Distribution: Latin America Conference and Exposition (T\&D-LA), pp. 1-6, 2012, IEEE.
[15] V. Farahani, B. Vahidi, and H. A. Abyaneh, "Reconfiguration and capacitor placement simultaneously for energy loss reduction based on an improved reconfiguration method," IEEE Transactions on Power Systems, vol. 27, no. 2, pp. 587595,2011

[16] S. Madeiro, E. Galvão, C. Cavellucci, C. Lyra, and F. Von Zuben, "Simultaneous capacitor placement and reconfiguration for loss reduction in distribution networks by a hybrid genetic algorithm," IEEE Congress of Evolutionary Computation (CEC), 2011, pp. 2178-2185, 2011, IEEE.

[17] M. J. Kasaei and M. Gandomkar, "Loss reduction in distribution network using simultaneous capacitor placement and reconfiguration with ant colony algorithm," 2010 Asia-Pacific Power and Energy Engineering Conference, pp. 1-4, 2010, IEEE.

[18] J. G. Vlachogiannis and K. Y. Lee, “A comparative study on particle swarm optimization for optimal steady-state performance of power systems," IEEE Transactions on Power Systems, vol. 21, no 4, pp. 1718-1728, 2006.

[19] A. Moradi and M. Fotuhi-Firuzabad, "Optimal switch placement in distribution systems using trinary particle swarm optimization algorithm," IEEE Transactions on Power Delivery, vol. 23, no. 1, pp. 271-279, 2008.

[20] A. Moradi, M. Fotuhi-Firuzabad, and M. Rashidi-Nejad, "A reliability cost/worth approach to determine optimum switching placement in distribution systems," 2005 IEEE/PES Transmission \& Distribution Conference \& Exposition: Asia and Pacific, pp. 1-5, 2005, IEEE.

[21] J. H. Teng and C. N. Lu, "Feeder switch relocation for customer interruption cost minimization," IEEE Transactions on Power Delivery, vol. 17, no. 1, pp. 254-259, 2002.

[22] J. H. Teng and Y. H. Liu, "A novel ACS-based optimum switch relocation method," IEEE Transactions on Power Systems, vol. 18, no. 1, pp. 113-120, 2003.

[23] P. M. Carvalho, L. A. Ferreira, and A. C. Da Silva, "A decomposition approach to optimal remote controlled switch allocation in distribution systems," IEEE Transactions on Power Delivery, vol. 20, no. 2, pp. 1031-1036, 2005.

[24] A. A. Esmin, G. Lambert-Torres, A. Z. De Souza, "A hybrid particle swarm optimization applied to loss power minimization," IEEE Transactions on Power Systems, vol. 20, no. 2, pp. 859-866, 2005.

[25] R. Manjunath, "Reconfiguration of distributed network using binary particle swarm optimization method," International Journal of Computer Sciences and Engineering 2018, vol. 6, no. 7, 1443-1445.

[26] T. Tafticht, K. Agbossou, M. L. Doumbia, and A. Cheriti, “An improved maximum power point tracking method for photovoltaic systems," Renewable Energy, vol. 33, no. 7, pp. 1508-1516, 2008. 